\title{
What Role Does Organizational Justice Play in the Relationship between Trust and Knowledge Sharing?
}

\author{
Yunkuai Zhang ${ }^{\mathrm{a}}$ and Ping Wang ${ }^{\mathrm{b}}$ * \\ Zhejiang Sci-Tech University, School of Economics and Management, Hang Zhou, China 310018 \\ a17858406322@163.com, bw190923@163.com \\ *Corresponding author
}

Keywords: Trust, Organizational Justice, Knowledge Sharing

\begin{abstract}
The trust of members and members in the organization has a positive effect on the knowledge sharing within the organization. Employees' knowledge sharing behaviours are also prone to occur when employees believe in supervisory leadership and decision-making, trust their colleagues' ability to work, and get help from colleagues when they encounter difficulties. Trust can reduce the uncertainty of each other, enhance the cohesion of the organization, and enhance the knowledge sharing in the organization. Whether or not the organization has a fair environment will affect the strength of trust in the organization and promote knowledge sharing. The open proposal system, reasonable reward policy, and transparent decision-making process will all promote knowledge sharing behaviour. Therefore, trust has a direct positive impact on knowledge sharing, and organizational justice can play a role in the regulation of trust and knowledge sharing.
\end{abstract}

\section{Introduction}

In the age of knowledge economy, managers are fully aware that knowledge is an important resource that affects the development of enterprises, and it is also the key to their competitive advantage. Knowledge sharing can help companies build a resource-rich knowledge base and provide a driving force for the development of enterprises (Lin LU and Xue-Ling LIANG,2009). The company's core competence also comes from knowledge sharing among employees (Grant RM, 1996). Knowledge sharing can positively promote the reduction of production costs, the improvement of efficiency, the development of new products, and the improvement of corporate creativity and performance (Lin, 2007). Therefore, knowledge sharing has become one of the organizational activities that corporate managers attach particular importance to (Tian-Qi NIE, 2017). Knowledge sharing arises among employees, and the degree of trust among employees has no doubt about their sharing behavior (Wan-Kun ZHOU 2016), and it is also a prerequisite basis for sharing individual knowledge with others (Lu L\&Leung $\mathrm{K}$ et al., 2006). Trust can promote the initiative of the sharer and receiver of knowledge sharing, reduce the cost of knowledge exchange, and improve the understanding and absorption of knowledge (Mi ZHOU et al, 2006). Knowledge sharing as a kind of exchange activity, the higher the degree of trust among members, the more confident they are about the future possible returns of others, and thus they are more willing to share knowledge with others (Wei-Dong LI, Hong LIU, 2014).

In the process of knowledge dissemination, how to establish a fair knowledge sharing environment has important influence on the establishment of trust relationships and the promotion of knowledge sharing. In this society where equity is increasing, social equity affects social order and stability. Organizational fairness affects employee behavior and ultimately leads to organizational performance and competitiveness. Once employees feel that they have not been treated fairly by the organization, or that their efforts have not received the due rewards, their work enthusiasm will be reduced. Nowadays, organizational justice has been relatively mature and extensively studied. Ya LIU (2003) studied the specific role of organizational fairness in employee attitudes and behaviors. Ibragimova (2006) believes that a fair organizational climate has a positive effect on the occurrence of knowledge sharing behavior. Organizational fairness as an 
organizational member's fair feelings about the organization's policies, systems, and behaviors related to their own personal interests (Feng LI, 2008). Emphasizing the organization's construction of a fair atmosphere is an important strategy for promoting internal knowledge sharing within the company (Qian-Xian LI,2014). Therefore, for the organization, the organization needs to create a fair and harmonious atmosphere and give employees a positive experience to encourage and support employees' knowledge sharing behavior.

It can be seen that knowledge sharing may not only be influenced by trust, but also may be regulated by the organization's fairness in the process of trust affecting knowledge sharing. Therefore, it is necessary to explore the mechanisms of trust and organizational fairness affecting knowledge sharing so as to provide management suggestions for the effective sharing of knowledge within the organization.

\section{Theoretical Review}

\subsection{What is Trust?}

Trust is a relatively stable personality trait created through social learning (Rotter, 1967). In an organization with a common norm, trust is a member's expectation of mutual honesty and cooperative behavior (Fukuyama, 1995). Chinese people's interpersonal trust is more dependent on emotional factors (Zhong-Fang YANG and Si-Qing PENG, 1999), with the colors of their rights and their close connection with their loyalty (Ke LIANG, 2002).

In a study of trust, Kee \& Knox (1970) proposed a scenario where a person in a disadvantageous position recognizes the possibility of being hurt or sold by others; the risk that trust can be perceived as being someone depends on the performance of others (Coleman, 1990); One party is at a disadvantage because of another's behavior, because one side thinks that others' specific behavior is very important to them (Mayer, Davis \& Schoorman, 1995). Trust is an optimistic expectation of the result (Hosmer \& Tone, 1995), and it is also an expectation or belief that the future behavior of others will benefit their own interests (Robinson, 1996). In other words, trust is a psychological state that is willing to accept vulnerability (Sitkin, 1993; Rousseau \& Burt, 1998), which is the expectation and assumption of the individual's influence on others and on their own earnings (Romano, 2003).

Thus, we can also see the three basic meanings of trust: (1) When a person trusts another person, he believes that the behavior of others is good faith; (2) Trust represents the risk that they are willing to bear due to the actions of the other person. (3) Trust means reliance on others, which means that their own results are affected by the other party.

For the trust structure, most scholars believe that it is a multi-dimensional structure (Wei-Min LI, Yuc-Heng LIANG, 2002), mainly including two-dimensional and three-dimensional views.

Mishra (1984) divided the internal trust of the organization into upward trust and downward trust, while Yu-Min XI (2004) considered this relationship to be one-way. The organization members are trust parties and the organization is the trusted party. Nyhan \& Marlowe (1997) divided trust into three dimensions: trust of the colleague, trust of the supervisor, and trust of the organization. Juan-Ru WANG (2012) summed it up into supervisor trust and colleague trust. The most influential one is McAllister (1995) divided trust into cognition-based trust and affect-based trust from the perspective of the trustworthy person.

\subsection{What is Knowledge Sharing(KS)?}

In the study of knowledge sharing, different scholars define their knowledge sharing from different perspectives, mainly from the perspectives of information communication, organizational learning, knowledge transformation and knowledge transfer, which is shown in table1:

Even KS is defined from different perspectives, some of them share some common characteristics: whether KS is a kind of behavior or process involves two subjects, which is, KS is the sharing of knowledge through interaction between knowledge owners and knowledge acceptors.

On the division of $\mathrm{KS}$, the current main is divided into single-dimensional and multi- 
dimensional.

Table 1. Definition of Knowledge Sharing

\begin{tabular}{|c|c|c|}
\hline Perspective & Author & Definition \\
\hline \multirow{2}{*}{$\begin{array}{l}\text { Information } \\
\text { communication }\end{array}$} & Lee (2001) & $\begin{array}{l}\text { KS is the act of transferring information among individuals, } \\
\text { groups and organizations of two organizations. }\end{array}$ \\
\hline & $\begin{array}{l}\text { Hooff \& Ridder } \\
\text { (2004) }\end{array}$ & $\begin{array}{l}\text { KS is the process of exchanging knowledge among } \\
\text { individuals and developing them into organizational } \\
\text { knowledge. }\end{array}$ \\
\hline \multirow[b]{2}{*}{$\begin{array}{l}\text { Organizational } \\
\text { learning }\end{array}$} & Lin Dongqing & $\begin{array}{l}\text { KS is the act of sharing knowledge through different } \\
\text { channels and means within organizations. }\end{array}$ \\
\hline & $\begin{array}{l}\text { Sheng-Tai ZHANG } \\
\text { and Ya-Zhou } \\
\text { WANG(2015) }\end{array}$ & $\begin{array}{l}\text { KS is a kind of behavioral process of organizing the } \\
\text { optimization result of system design and arrangement }\end{array}$ \\
\hline \multirow{3}{*}{$\begin{array}{l}\text { Knowledge } \\
\text { transformation }\end{array}$} & Nonaka (1995) & $\begin{array}{l}\text { KS is the process of mutual transformation of tacit } \\
\text { knowledge between individuals }\end{array}$ \\
\hline & Ipe (2003) & $\begin{array}{l}\text { KS is not only a process of transformation, but also a process } \\
\text { of making others understand, absorb and use it }\end{array}$ \\
\hline & Jiang WEI(2006) & $\begin{array}{l}\text { KS is the process of three: individual into individual process; } \\
\text { organization into individual process; organization into } \\
\text { organizational process }\end{array}$ \\
\hline \multirow{2}{*}{$\begin{array}{l}\text { Knowledge } \\
\text { transfer }\end{array}$} & Wijhoven (2003) & $\begin{array}{l}\text { KS is a combination of the two behaviors of knowledge } \\
\text { transferors including externalizing their own knowledge and } \\
\text { knowledge recipients internalizing others' knowledge }\end{array}$ \\
\hline & Helmastadte ( & $\begin{array}{l}\text { KS is a voluntary and knowledge-based interaction process } \\
\text { among actors }\end{array}$ \\
\hline
\end{tabular}

Scholars will be one-dimensional KS from the behavior and attitude of two aspects to be divided. Based on behavioral aspects: knowledge sharing behavior (Lu,2006); tacit knowledge sharing (Lin,2007). Based on attitudes: willingness to share knowledge (Ehow \& Ehan, 2005); knowledge sharing attitude (Hwang \& Kim, 2007); knowledge sharing tendencies (Wah \& Evers, 2007).

Hooff \& Ridder (2004) understood KS as two dimensions: contribution and collection of knowledge, which was consistent with the idea of KS by Tao LI and Bing WANG (2003); Jiang-Tao SHI (2012) divided KS into knowledge output and knowledge absorption. Bock \& Kim (2002) divided KS into three dimensions: the attitude of knowledge sharing, the willingness of knowledge sharing and the behavior of knowledge sharing.

\subsection{What is Organizational Justice(OJ)?}

The fair research in the organization began with the theory of fairness of Adams (1965). He believes that the sense of fairness comes from two kinds of comparisons. One is the comparison of the investment rate of return of oneself with others, and the other is the comparison of the current and previous investment rate of return. A fair rate is produced when the ratio is equal; on the contrary, it is unfair (Xin-Chao WANG and Yan WU, 2002). This theory emphasizes the equivalence of individual inputs and results obtained (Charash \& Spector, 2001; Colquitt et al., 2001). Judging the fairness through the comparison of results, this "fairness" is a subjective feeling (Wei LI, 2014), and organizational justice is the fair feeling of people in the organization (Yu-He LI and Li-Rong LONG et al., 2003).

OJ is the subjective perception of whether employees are impartial when assigning resources to organizations and determining rewards and penalties(Scholl \& Cooper,1987); whether individuals are aware of whether or not an organization treats them fairly (Greenberg, 1990; Chao-Ping LI and Kan SHI, 2003); it is the fair perception of the organization's internal environment (James, 1993); it is the fair feeling of people in the organization about the organization policies, measures, and results related to the individual (Ye LI and Li-Rong LONG et al., 2003). 
To sum up, this study defines OJ as: In the work environment, employees' perception of whether the organization treats them fairly.

At present, the division of the organization's fairness in the academic circle has become more mature, mainly divided into single-dimensional and multidimensional. From the initial unilateral structure of fair distribution of Adams (1965) to the most common and mature today, it is the two dimensions of distribution fairness and procedural fairness. Some scholars believe that fairness and fair distribution alone are not enough to give employees an unfair feeling because employees' perceptions of relative performance and reward are often inaccurate (Porter \& Lawler, 1965; Greenberg \& Mc Carty, 1990). Bies \& Maog (1986) divides the organization's equity into three dimensions: distributive justice, procedural justice and interactional justice. Colquitt \& Greenberg, (2003) believe that interactive fairness can be divided into two dimensions: interpersonal fairness and information fairness, and confirmatory factor analysis supports this point.

\subsection{The Relationship Between Trust and Knowledge Sharing}

In order to achieve the sharing of knowledge, people must first learn to trust each other (Senge, 2008). Once unconditional trust is created, the will to share knowledge is formed (Bao-Zhong YE, 2014). People must have trust and knowledge to be shared (Senge, 1997). Trust is an important factor influencing knowledge sharing (P Wang, TW Tong, 2004).

Trust relationship is an interactive process. Believing each other as upright, trustworthy, and willing to take on the risks involved, it is the organization's glue (Bao-Zhong YE, 2014). Research shows that trust among team members is the basis for inducing tacit knowledge sharing behavior among team members (Nonaka, 1995; Toyama \& Konno, 2007). As the trust of team members increases, mutual knowledge sharing increases (Nelson \& Cooperrider, 1996). At the same time, it can reduce each other's psychological uncertainty and increase each other's psychological commitment (Higgs M, 2005), without fear of being used by the other (Bradach \& Eccles, 1989), thus enhancing knowledge sharing in the team. Zaheer (2006) also believes that the organization has a close relationship of trust that facilitates knowledge sharing; trust has a positive effect on knowledge sharing (Yan-Fei WANG, 2012).

The higher the supervisor's trust in his subordinates, the higher the supervisor's willingness to share knowledge with subordinates (Stevenson, 1997). When employees agree with the ability of other colleagues to work and their work is consistent, employees believe that knowledge sharing will also be rewarded by colleagues. In this context, employees also tend to generate altruistic behaviors and increase knowledge sharing (Juan-Ru WANG, 2012); employees' trust in supervisors can create common goals, thereby increasing knowledge sharing among members (Gambetta, 1988). The occurrence of knowledge sharing behavior (Cao Keyan, 2008). This is because employees believe that knowledge sharing will be recognized by supervisors (Juan-Ru WANG, 2012), and raising the trust relationship between employees, supervisors, and organizations can increase employees' willingness to share knowledge (Bao-Zhong YE, 2014).

Based on the above analysis, it is necessary to maintain trust among members who share knowledge within the organization, whether they are subordinates and supervisors, or members and members. Only in this way, both parties have the willingness to share knowledge.

\section{Theoretical Model}

Organizational justice plays a regulatory role in the relationship of more research variables, such as OJ plays a positive regulatory role in the impact of transactional leadership on employee performance (Nan WANG, 2015) and employee work stress on work involvement (Yi-Yang HU, 2015). From this, it can be seen that the fairness of the organization's members as regards the organization's policies and the fairness of the system may affect the individual's willingness to perform beneficial behaviors for the organization. From the perspective of this study, there is currently no study that uses organizational justice as a moderating variable to discuss its impact on trust and knowledge-sharing relationships. However, in studies that use trust as an independent variable, some scholars have studied the regulation of organizational justice effect. 
Jun ZHAO et al. (2013) found that OJ has a significant triple effect in the impact of organizational trust on job satisfaction. When the fairness of assignment and fairness of procedure are high, organizational trust has the strongest positive effect on job satisfaction, and vice versa weak. Procedural fairness and distribution fairness have a positive effect on job satisfaction (McFarlin \& Sweeney, 1992), and procedural fairness has more explanatory power for organizational variables (Folger, 1989). If employee compensation and contribution match, then employees will have a higher level of trust in the organization; as for procedural fairness, employees will regard it as their own social status information in the organization. If the perceived organizational process is fair, employees will think that organizations who value and trust them will have a stronger altruistic motivation (Tyler, 1989). When the distribution fairness and procedural fairness are high, employees will have a higher positive psychological perception of the organization, and high trust will bring about high job satisfaction (Jun ZHAO et al., 2013). At the same time, job satisfaction has a positive impact on human behavior. The important influence (Shi-Hong WANG and Yuan-Dong GU, 2012). Job satisfaction is the evaluation of the positive emotional state of individual work (Fry, 1986), or the general attitude of the individual in the work (Zuo-Hao HU, 2006). The emotions, attitudes, and sense of responsibility displayed by individuals at work have a significant impact on knowledge sharing (Chih-Chien, 2007; Kurt Matzler, 2011). Shu-Hua ZHANG (2005) research shows that there is a certain correlation between job satisfaction and knowledge sharing. Bing-Cheng WANG (2011) research confirmed that employees with high job satisfaction are more willing to share their knowledge, develop together with colleagues, and improve the overall level of the organization.

De-Jun CHENG (2011) finds that distributional equity positively regulates the relationship between interpersonal trust and organizational citizenship behavior. Organizational citizenship behavior refers to voluntary performance (Organ, 1988), an act outside the role (William \& Anderson, 1991), and this behavior is beneficial to organizational members and organizations (Hai-Lin SU, 2006). The survey by MertinsK et al. (2003) shows that people regard knowledge management as a burden outside formal work, especially knowledge sharing. KD Joshi, S Sarker (2006) also pointed out that knowledge transfer should be seen as a voluntary extra-role behavior performed by an employee. It can be seen that knowledge sharing has the attribute of organizational citizenship, and it belongs to the informal activities outside the role of employees (Rui YAN et al., 2011).

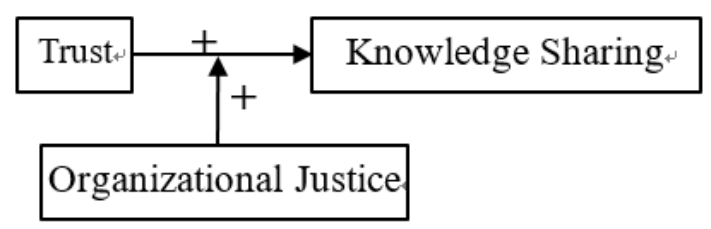

Figure 1. Theoretical model.

In summary, OJ has been proved to play a positive role in the impact of trust on job satisfaction and trust on organizational citizenship behavior. Job satisfaction will directly affect the knowledge sharing behavior of employees. Knowledge sharing behavior itself is as an organizational citizenship behavior, it can be speculated that OJ may affect the relationship between trust and knowledge sharing. Organizational trust in the process of significant positive impact on knowledge sharing, organizational justice creates an open cultural atmosphere for it, and it is more conducive to employees' knowledge sharing behavior (Xiao YANG, 2017). When employees in an organization are actively engaged in work with the hearts of a trusted organization and colleagues, a fair environment in the organization will affect whether employees are willing to continue to believe in the organization, and then choose their own level of knowledge sharing and contribution to the organization. It can be seen that whether the trust in the organization can enhance the degree of knowledge sharing among employees is regulated by the organization's fairness. That is, the stronger the organization's sense of justice, the stronger the influence of trust on knowledge sharing. 
From this we can get the theoretical model shown in Figure 1.

\section{Conclusion}

Trust within an organization has a positive influence on knowledge sharing. When members of an organization believe that their colleagues are capable of working, and that their work is consistent with their words and deeds, they are able to get help from their colleagues when they encounter difficulties, and they are more willing to share their knowledge with colleagues. When the organization employees believe that managers' leadership, judgment, decision-making is conducive to the organization, the members are frank and take into account the needs of the members of the work, the knowledge sharing behavior of the members of the organization will also increase. Therefore, when there is a strong sense of trust among the members of the organization, the communication between them will be more frequent and have stronger cohesion. Members are more willing to do activities that are beneficial to the organization and promote the occurrence of knowledge sharing behavior. Organizational justice plays a regulatory role in the relationship between trust and knowledge sharing, organization of fair organization, and the stronger the role of trust in the organization in promoting knowledge sharing among employees.

Therefore, the trust between organizational members in the process of management is a factor that cannot be ignored when members share knowledge. First, companies need to increase their willingness to share knowledge by fostering trust relationships between employees and supervisors, employees, and organizations. Make trust visible in the enterprise, through the leader's lead by example, top-down employees know the benefits of knowledge sharing, continue to accumulate the organization and the executive's commitment to the past and improve the support of employees. Second, the organization needs to create a fair and harmonious atmosphere through the establishment of a public proposal system and a transparent management hierarchy, giving employees a positive experience to encourage and support employees' knowledge sharing behavior, and ultimately ensure the level of knowledge sharing within the organization.

\section{References}

[1] RM Grant. (1996) Prospering in dynamically competitive environments: organizational capability as knowledge integration. Organization Science, 7 (4),375-387.

[2] RC Nyhan. (1997) HA Marlowe. Development and Psychometric Properties of the Organizational Trust Inventory. Evaluation Review, 21(5),614-635.

[3] DM Romano. (2003) The nature of trust: conceptual and operational clarification. PhD Dissertation, Louisiana State University.

[4] Lu L., Leung K., Koch. (2006) Managerial Knowledge Sharing: The Role of Individual, Interpersonal, and Organizational Factor. Management and Organization Review, 2(1),15-41.

[5] Lin H F. (2007) Knowledge sharing and firm innovation capability: An empirical study. International Journal of Manpower, 28(3/4),315-332.

[6] KD Joshi, S Sarker. (2006) Examining the Role of Knowledge, Source, Recipient, Relational, and Situational Context on Knowledge Transfer among Face-to-Face ISD Teams. Hawaii International Conference on System Sciences, 7,148c-148c.

[7] Juan-Ru WANG, Yang Hao. (2012) Research on the Relationship of Trust, Team Interaction and Knowledge Sharing Behavior. Science of Science and Management, ,33(10),31-39.

[8] Jiang-Tao SHI (2012). Study on the Mechanism of Communication to Promote Knowledge Sharing Information Science,30(1),132-143.

[9] Shi-Hong WANG and Yuan-Dong Gu. (2012) Psychological Contract, Job Satisfaction and Knowledge Sharing Behavior of National Auditors. Auditing Research, 1,48-54. 
[10] Jun ZHAO, Xiang CAI, Shu-Song ZHAO. (2013) Effects of Organizational Trust on Job Satisfaction: Organizational Equity as a Moderator Variable. Soft Science, 6(27),89-93.

[11] Bao-Zhong YE. (2014). Research on the impact of organizational justice and trust on knowledge sharing. Technology Economics and Management Research, 9,27-31. 